\title{
Production of MA956 Alloy Reinforced Aluminum Matrix Composites by Mechanical Alloying
}

\author{
Luiz, Antonio Carlos Moutinho Gomes ${ }^{a}$, Dilermando Nagle Travessa ${ }^{a}$,Jose Luis González-Carrasco ${ }^{b, c}$, \\ Marcela Lieblich $^{b}$,Katia Regina Cardoso ${ }^{a *}$ \\ ${ }^{a}$ Universidade Federal de São Paulo - UNIFESP, Rua Talim, 330, CEP 12231-280, \\ São José dos Campos, SP, Brasil \\ ${ }^{b}$ Centro Nacional de Investigaciones Metalúrgicas - CENIM, Consejo Superior de Investigaciones \\ Cientificas - CSIC, Madrid, Spain \\ ${ }^{c}$ Centro de Investigación Biomédica en Red en Bioingeniería, Biomateriales y \\ Nanomedicina - CIBER-BBN, Zaragoza, Spain
}

Received: November 6, 2014; Revised: August 7, 2015

\begin{abstract}
Aluminum matrix composites (AMC) are attractive structural materials for automotive and aerospace applications. Lightweight, environmental resistance, high specific strength and stiffness, and good wear resistance are promising characteristics that encourage research and development activities in AMC in order to extend their applications. Powder metallurgy techniques like mechanical alloying (MA) are an alternative way to design metal matrix composites, as they are able to achieve a homogeneous distribution of well dispersed particles inside the metal matrix. In this work, aluminum has been reinforced with particles of MA956, which is an oxide dispersion strengthened (ODS) iron base alloy (Fe-Cr-Al) of high Young's modulus and that incorporates a small volume fraction of nanometric yttria particles introduced by mechanical alloying. The aim of this work is to investigate the use of MA to produce AMC reinforced with 5 and 10 vol.\% of MA956 alloy particles. Homogeneous composite powders were obtained after $20 \mathrm{~h}$ of milling. The evolution of morphology and particle size of composite powders was the typical observed in MA. The composite powders produced with 10 vol.\% MA956 presented a more accentuated decrease in particle size during the milling, reaching $37 \mu \mathrm{m}$ after $50 \mathrm{~h}$. The thermal stability of the composite and the existence of interface reactions were investigated aiming further high temperature consolidation processing. Heat treatment at $420{ }^{\circ} \mathrm{C}$ resulted in partial reaction between matrix and reinforcement particles, while at $570{ }^{\circ} \mathrm{C}$ the extension of reaction was complete, with formation in both cases of Al-rich intermetallic phases.
\end{abstract}

Keywords: aluminum matrix composite, MA956 alloy, powder metallurgy

\section{Introduction}

Aluminum matrix composites have, in general, improved properties at elevated temperatures, higher specific strength and wear resistance than unreinforced matrix alloy ${ }^{1-5}$. Composites reinforced by discontinuous phases were particularly promising due to easy processing and great possibility of applications in the transportation industry (automotive and rail), aerospace, recreation and infrastructure ${ }^{2-5}$.

Aluminum matrix composites reinforced with ceramic particles have already found several applications. However, they suffer from some drawbacks due to the high abrasiveness and brittleness of the ceramics. Intermetallics particles have been used as an alternative because of their lower abrasiveness and brittleness ${ }^{6-8}$. Intermetallics have also thermal expansion coefficients closer to the aluminum, resulting in a decrease of the residual stresses in the reinforcement-matrix interface, thus reducing problems related to thermal fatigue ${ }^{9}$.

Powder metallurgy (PM) has proved to be a very suitable method for processing of metal matrix composites because it

*e-mail: krcardoso@unifesp.br prevents reactions between matrix and reinforcement. But deleterious reaction products at intermetallic/matrix interfaces may also form during hot consolidation process or heat treatments, giving rise to brittle interphases ${ }^{6,8,10}$.

In this work, particles of an Fe-Cr-Al superalloy (MA956) developed for aerospace application were used as reinforcement in the aluminum matrix composite. MA956 is an oxide dispersion strengthened alloy (ODS) with $\alpha-\mathrm{Fe}$ matrix, commercially produced by mechanical alloying, combining good tensile strength and ductility at ambient temperature ${ }^{11,12}$. The processing route and the reinforcement by nanoparticles of yttrium oxide result in a combination of excellent strength and fabricability with outstanding oxidation and corrosion resistance at temperatures up to $1300{ }^{\circ} \mathrm{C}$, and reasonable creep strength. Despite the high density of the alloy, $7.25 \mathrm{~g} / \mathrm{cm}^{3}$ compared with aluminum alloys and ceramic compounds, the MA956 alloy has lower density when compared to other superalloys. Also relevant is its high Young's modulus ( $220 \mathrm{GPa})$ and its thermal 
expansion coefficient, closer to that of aluminum than that of ceramic compounds such as $\mathrm{SiC}$.

In this work, $\mathrm{Al} / 5$ and 10 vol.\% MA956 composites were obtained by MA. This process was selected to prevent reactions during the reinforcement dispersion step. Composite powders obtained after milling times up to $50 \mathrm{~h}$ were characterized to find out the relationship among the stages of MA and the powder characteristics. The composite powder was submitted to heat treatments with the aim of evaluating the thermal stability of composite and the existence of interface reactions.

\section{Experimental Procedure}

Commercial pure aluminum powder (99.5\%) supplied by ALCOA, with particles size smaller than $100 \mu \mathrm{m}$ was blended with 5 and 10 vol. \% of MA956 alloy powder. The MA956 alloy was produced by INCO Alloys International with the following composition $\mathrm{Fe}-20 \mathrm{Cr}-4.5 \mathrm{Al}-0.5 \mathrm{Ti}-0.5 \mathrm{Y}_{2} \mathrm{O}_{3}$ (wt.\%). The milling was carried out in high energy Pulverisette planetary ball mill at $200 \mathrm{rpm}$ with a ball to powder weight ratio of 20:1 under argon atmosphere. The milled powders were collected at regular intervals of 2.5, 5, 10, 20 and $50 \mathrm{~h}$ and analyzed by X-ray diffraction (XRD) in a Rigaku, Ultima IV diffractometer and by scanning electron microscope (SEM) in a FEI INSPECT microscope equipped with energy dispersive X-ray (EDS) detector. For SEM characterization, small amounts of powders were embedded into Bakelite and prepared by conventional metallographic techniques. A laser particle size analyzer, Cilas 1190L, was used to determine the particle size distribution of powder milled for $50 \mathrm{~h}$. Differential scanning calorimetry (DSC) measurements were carried out using a Netzsch DSC 204 F1 FÊNIX. Powder samples milled for $50 \mathrm{~h}$ were heated at constant rate of $10{ }^{\circ} \mathrm{C} / \mathrm{min}$ under a nitrogen atmosphere up to $570^{\circ} \mathrm{C}$. Cold compacted samples were heat treated at temperatures based on DSC peaks with the aim of investigate the thermal stability of composite and the reaction products between the reinforcement phase and aluminum matrix. The heat treated compacted samples were characterized by XRD, SEM and EDS analysis.

\section{Results and Discussion}

Micrographs shown in Figure 1 present the morphological evolution of powder with milling time. In the early stages of milling, until $2.5 \mathrm{~h}$, the events of plastic deformation and cold welding prevail. The tendency at this stage is that the flake-like particles resulted from the severe plastic deformation, weld together to form large particles presenting a characteristic layered structure, Figure 1a. Eventually the reinforcement particles are trapped between these layers

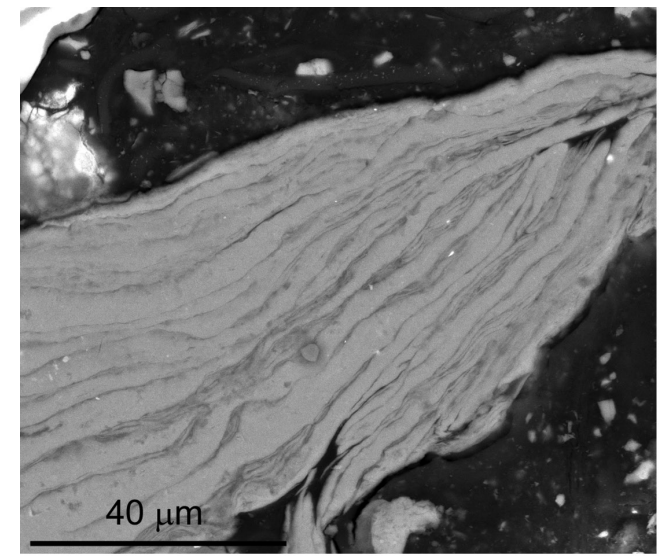

(a)

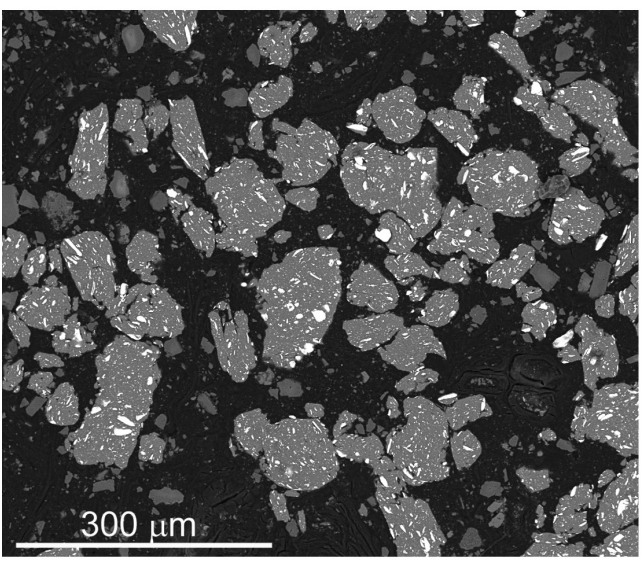

(c)

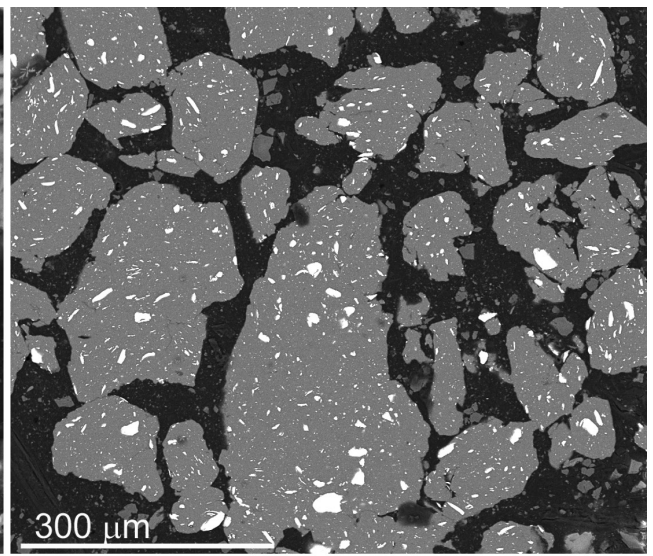

(b)

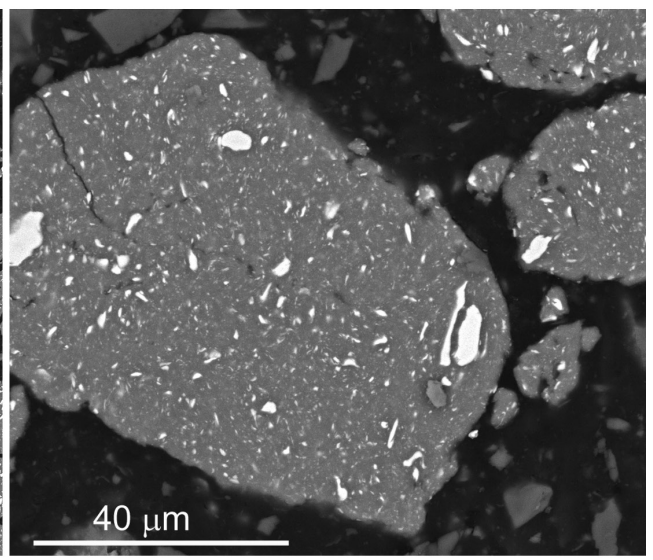

(d)

Figure 1. SEM micrographs obtained by back scattered electrons. (a) Al_5 vol.\%MA956 milled for 2.5 h; (b) Al_5 vol.\% MA956 milled for 20 h; (c) Al_10 vol.\% MA956 milled for 20 h; (d) Al_10 vol. \% MA956 milled for $50 \mathrm{~h}$. 
and with increase in milling time, their complete insertion into the aluminum particles takes place, Figure $1 \mathrm{~b}, \mathrm{c}$ and $\mathrm{d}$. As the deformation progresses, the particles work harden and the tendency to fracture predominates over cold welding resulting in the refining of particle size. The composite powders produced with 10 vol.\% MA956 presented a more accentuated decrease in particle size during the milling, which can be observed by comparing the micrographs of Figures $1 \mathrm{~b}$ and $\mathrm{c}$ from powders milled for $20 \mathrm{~h}$. Particle size distribution of samples milled for $50 \mathrm{~h}$, measured by laser diffraction using Cilas 1190L analyzer, confirmed this observation. The median value from the histograms (defined as size where $50 \%$ of the particles are larger and smaller) was taken as the average particle size, resulting in $97 \mu \mathrm{m}$ for composite with 5 vol.\% MA956 and $37 \mu \mathrm{m}$ for the one with 10 vol.\% MA956.

The presence of large hard particles into the Al soft matrix gives rise to a high rate of production of geometrically necessary dislocations near the particles and to large local strain gradients. The density of such dislocations is proportional to the strain gradient, i.e. the amount of plastic strain divided by the microstructural scale over which this gradient is created $^{13}$. The increase in volume fraction (to 10 vol.\%) of reinforcement phase, MA956 alloy, decreases the interparticle spacing, increasing the dislocation density and therefore the work hardening rate of the aluminum matrix. As a result, the fracture process is started earlier when the reinforcing volume is higher. This high density of dislocations is also a strong driving force for faster substructure generation, and contributes to the grain refinement process ${ }^{13,14}$. The composite produced with 10 vol.\% MA956 presents, after $50 \mathrm{~h}$ of milling, a diffraction pattern with broader peaks than that for 5 vol.\% MA956 one, which is representative of higher strain and finer crystal size. Figure 2 shows some examples of X-ray diffraction patterns of mechanically alloyed powder as a function of milling time. Only peaks related to the Al and $\alpha$-Fe phases are present.

Figure 3 presents the DSC curves of composite powders after milling for $50 \mathrm{~h}$. Three peaks are observed for composite with 5 vol.\% MA956 at 314,414 and $530{ }^{\circ} \mathrm{C}$, while only two peaks can be determined for sample with 10 vol.\%, at 321 and $531{ }^{\circ} \mathrm{C}$. The peak at $530{ }^{\circ} \mathrm{C}$ presents the same intensity for both samples whilst the other coincident peak at about $320^{\circ} \mathrm{C}$ is much more intense, sharp and well defined in the composite with 10 vol.\% of reinforcement phase, probably due the higher volume fraction of reinforcement particles and so a greater volume of reaction phase.

Cold compacted samples were submitted to heat treatment at $420^{\circ} \mathrm{C}$ for 1 and $24 \mathrm{~h}$ and at $570{ }^{\circ} \mathrm{C}$ for $1 \mathrm{~h}$ with the aim to find out the phases resulting from reactions between the aluminum matrix and the MA956 particles. The cold compacted Al_5 vol. \% MA956 composite submitted to $420^{\circ} \mathrm{C}$ for $1 \mathrm{~h}$ already shows indication of reaction between the matrix and the reinforcement particles. Figures $4 a$ and $b$ show examples of backscattered images of this composite where the aluminum matrix appears black, the MA956 alloy appears white and the dark grey phase corresponds to the reaction products. Results from EDS analyses performed in the spots indicated by the numbers 1,2 and 4 in Figure 4a are shown in the table inserted in Figure 4. These results suggest that the dark grey phase, spot 2 , is an intermetallic phase enriched in $\mathrm{Al}$, with composition near of the $\mathrm{Al}_{3} \mathrm{Fe}$ phase, while the surrounding white phase, spot 1 , seems to be the $\alpha$-Fe phase depleted in Cr. Particles as that of spot 4 which does not undergo appreciable reaction maintain the MA956 composition. The results after $24 \mathrm{~h}$ at $420^{\circ} \mathrm{C}$ were similar except that the reaction occurred to a greater extension, as showed in Figure 5a.

The increase of temperature to $570{ }^{\circ} \mathrm{C}$ resulted in a complete reaction of reinforcement with aluminum matrix. The SEM micrograph of Figure 5b shows an example of this condition.

Cold compacted samples of Al_10 vol.\% MA956 did not sinter during the heat treatment, so the metallographic preparation of such samples was not possible. Thereby, for SEM observation, loose powders milled for $50 \mathrm{~h}$ were heated up to $330{ }^{\circ} \mathrm{C}$ and up to $570{ }^{\circ} \mathrm{C}$ in the DSC furnace, embedded into Bakelite and prepared by conventional metallographic techniques. Figure 6 shows examples of composite particle powders heated up to $570^{\circ} \mathrm{C}$, where the inner reinforcement

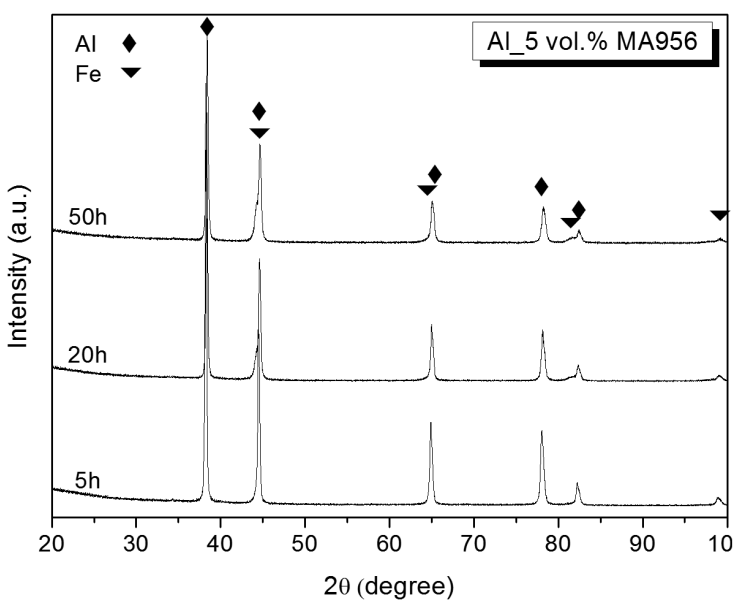

(a)

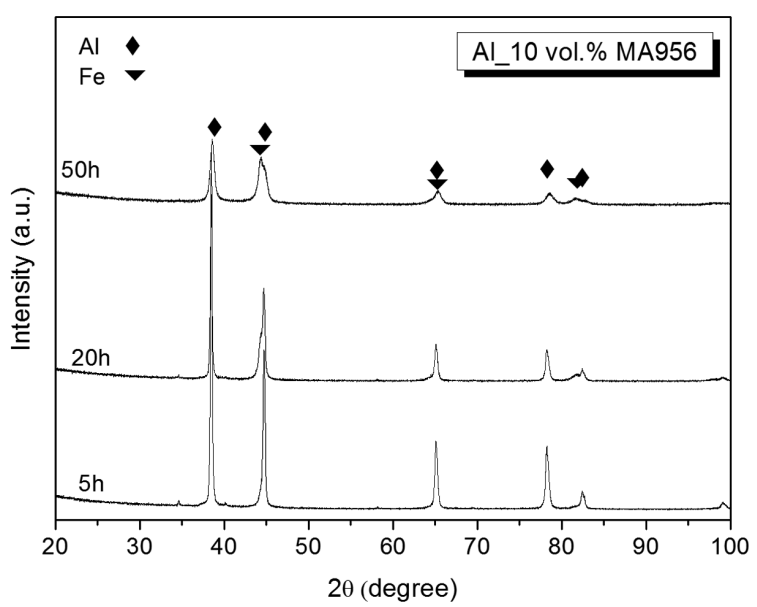

(b)

Figure 2. XRD patterns of mechanically alloyed powder as a function of milling time. (a) Al_5 vol.\% MA956; (b) Al_10 vol.\% MA956. 
particles have almost fully reacted. Figure $6 \mathrm{~b}$ presents the results of EDS analyses performed in the spots indicated by the numbers 1,2 and 3 . These results suggest that the white

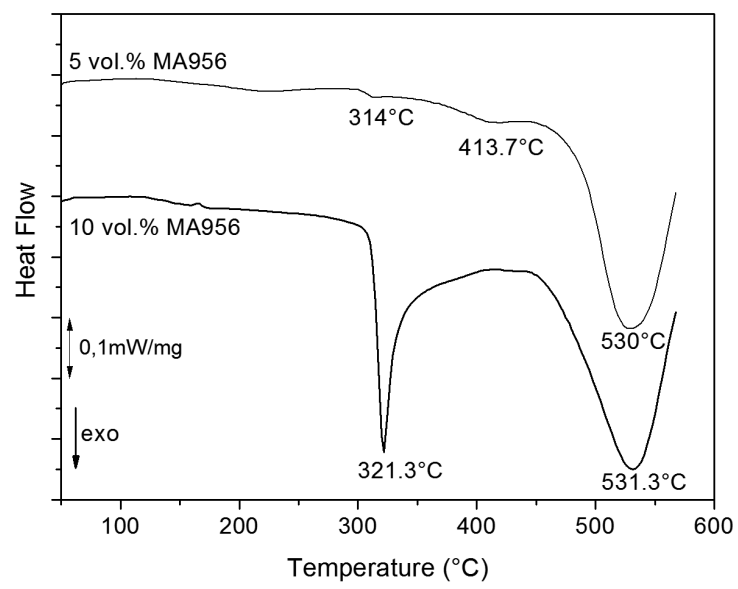

Figure 3. DSC curves of composite powders milled for $50 \mathrm{~h}$ (the heating rate of DSC is $10^{\circ} \mathrm{C} / \mathrm{min}$ ). phase, spot 1 , is the remaining $\alpha$-Fe (MA956 alloy), while the grey phase, spot 2, is an intermetallic phase enriched in Al, similar to that found in the Al_5 vol.\% MA956. The surrounding phase, spot 3 , is the aluminum matrix enriched in $\mathrm{Cr}$ and $\mathrm{Fe}$. Figure 6c shows a EDS mapping performed in the region of Figure $6 \mathrm{~b}$. The samples heated up to $330^{\circ} \mathrm{C}$ did not show any evidence of reaction by SEM, even when the temperature was maintained for $30 \mathrm{~min}$.

The identification of phases formed by the reaction between the MA956 alloy particles and the aluminum matrix during the heat treatments was performed by X-ray diffraction. Figures $7 \mathrm{a}$ and $\mathrm{b}$ show the X-ray patterns for the composites produced with 5 vol.\% MA956. It was observed after the treatment at $420{ }^{\circ} \mathrm{C}$ the formation of $\mathrm{AlFe}_{3}$ (ICDD No. 050-0955), $\mathrm{FeAl}_{3}$ (ICDD No. 001-1265) and $\mathrm{Al}_{6} \mathrm{Fe}$ (ICDD No. 047-1433) phases, while after $570{ }^{\circ} \mathrm{C}$ the main reaction phase is the intermetallic $\mathrm{Al}_{13} \mathrm{Fe}_{4}$ (ICDD No. 029-0042). Most of these intermetallics are equilibrium phases, present in the Al-Fe phase diagram. No ternary phase with Cr was identified. The patterns for the composite Al_10 vol.\% MA956, showed in Figures $7 \mathrm{c}$ and d, are very similar except by the higher
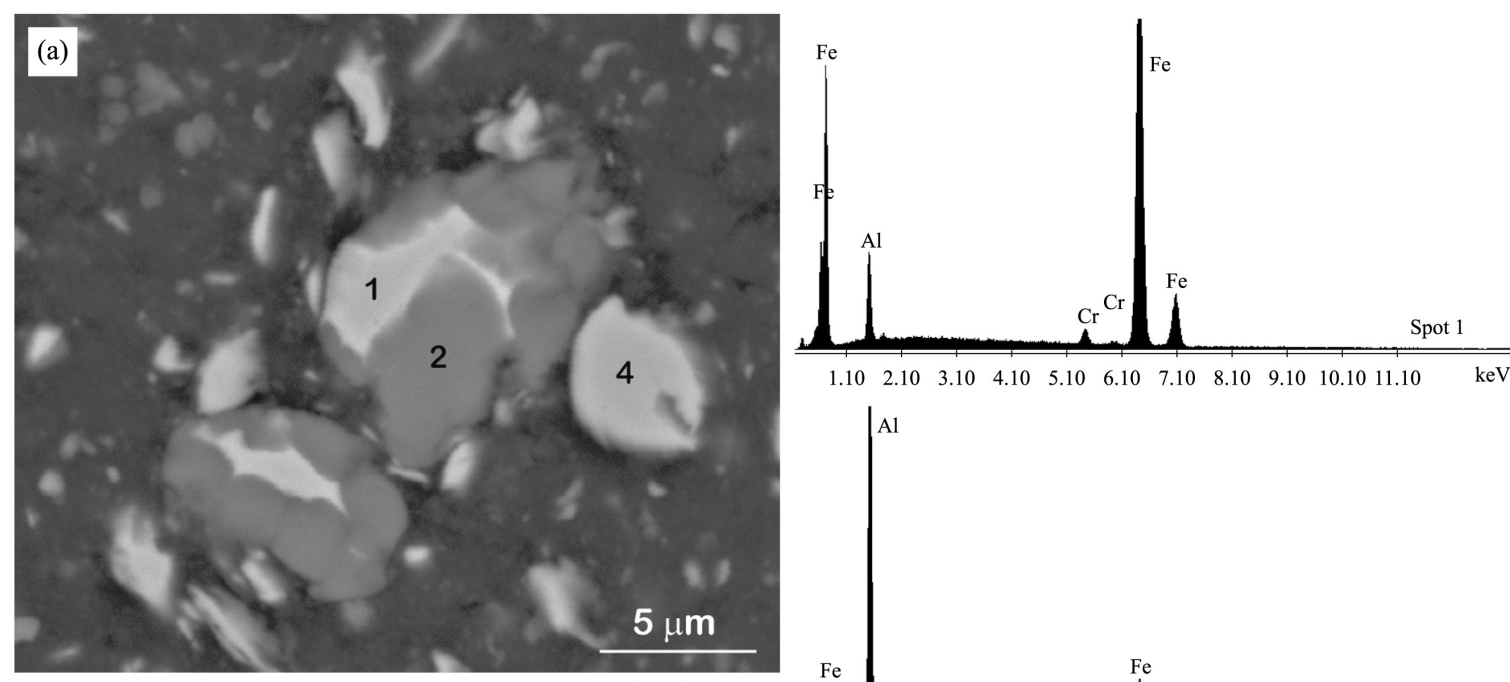

$\begin{array}{lllllllllllll}1.10 & 2.10 & 3.10 & 4.10 & 5.10 & 6.10 & 7.10 & 8.10 & 9.10 & 10.10 & 11.10 & \mathrm{keV}\end{array}$

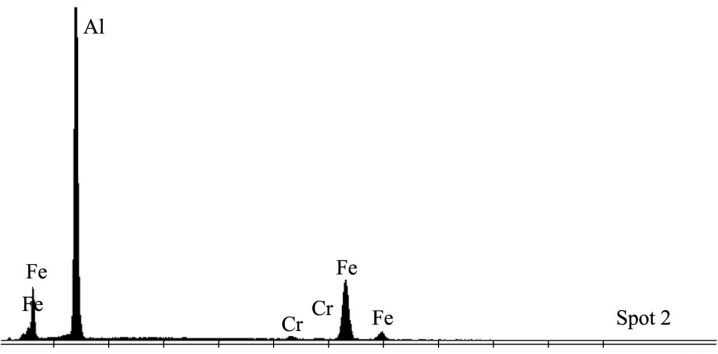

$\begin{array}{llllllllllllll}1.10 & 2.10 & 3.10 & 4.10 & 5.10 & 6.10 & 7.10 & 8.10 & 9.10 & 10.10 & 11.10 & \mathrm{keV}\end{array}$

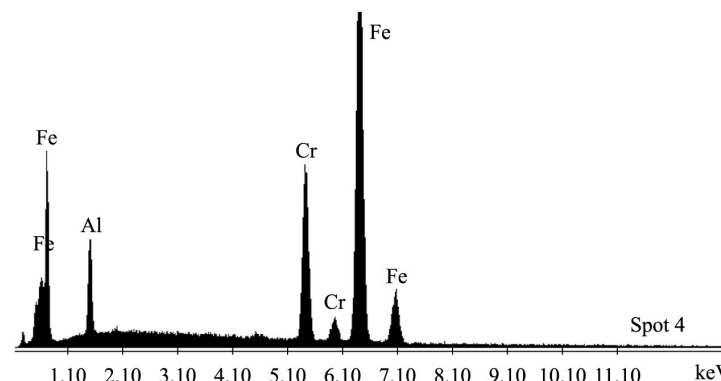

$\begin{array}{llllllllllll}1.10 & 2.10 & 3.10 & 4.10 & 5.10 & 6.10 & 7.10 & 8.10 & 9.10 & 10.10 & 11.10 & \mathrm{keV}\end{array}$

\begin{tabular}{|c|c|c|c|}
\hline Spot & $\mathbf{F e}(\mathbf{w t} \%$ / at\%) & $\mathbf{C r}(\mathbf{w t} \%$ / at\%) & $\mathbf{A l}(\mathbf{w t} \%$ / at\%) \\
\hline 1 & $90.3 / 83.1$ & $1.9 / 1.9$ & $7.8 / 15$ \\
\hline 2 & $36.9 / 22.2$ & $1.4 / 0.9$ & $61.7 / 76.9$ \\
\hline 4 & $74.2 / 68.2$ & $18.9 / 18.6$ & $6.9 / 13.2$ \\
\hline
\end{tabular}

Figure 4. (a) and (b) Backscattered image of a Al 5 vol. \% MA956 cold compact, heated for $1 \mathrm{~h}$ at $420{ }^{\circ} \mathrm{C}$. EDS spectra are relative to spots 1, 2 and 4 on Figure 3a. Inserted table presents the chemical composition by EDS obtained from spots 1, 2 and 4. 
intensity of peaks from the intermetallic phases resulting from their higher volume fraction.

Results show that the reaction proceeds by the diffusion of aluminum into MA956 particles with formation of intermetallic phases in the particle/matrix interface. As the reaction seems to be controlled by $\mathrm{Al}$ diffusion into the MA956 particles, the stoichiometric relation between Al and $\mathrm{Fe}$ in the intermetallic phases tends to be richer in $\mathrm{Al}$

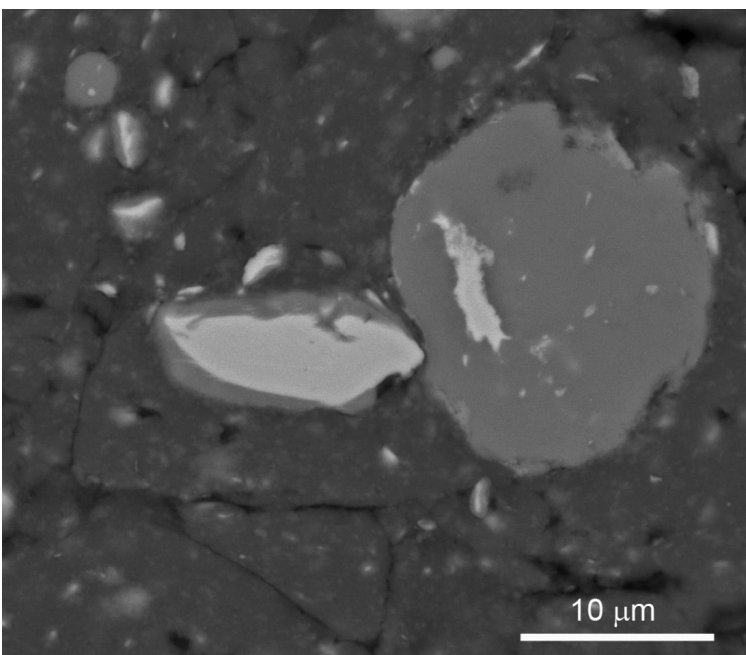

(a)

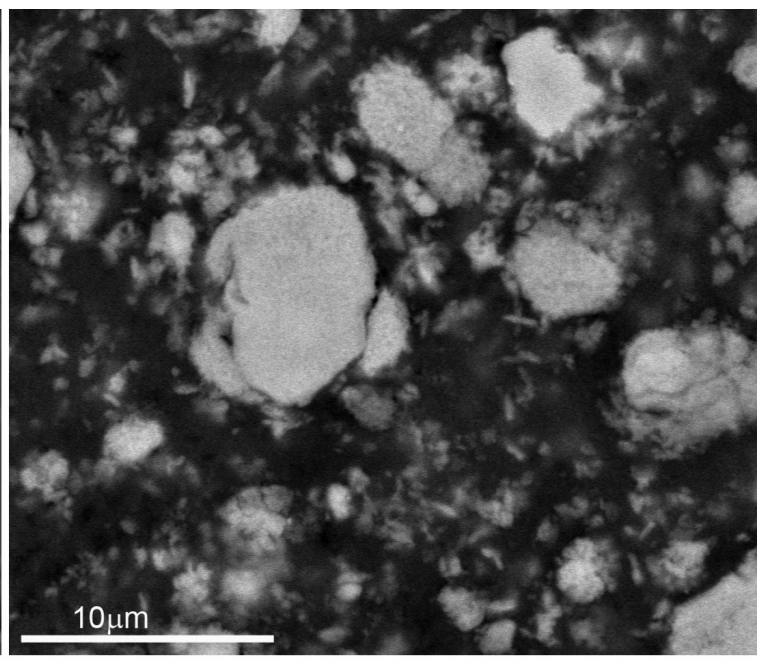

(b)

Figure 5. Backscattered image of Al_5 vol.\% MA956 cold compact, heated for $24 \mathrm{~h}$ at $420{ }^{\circ} \mathrm{C}$. (b) Backscattered image of Al_5 vol. \%MA956 cold compact, heated for $1 \mathrm{~h}$ at $570^{\circ} \mathrm{C}$.

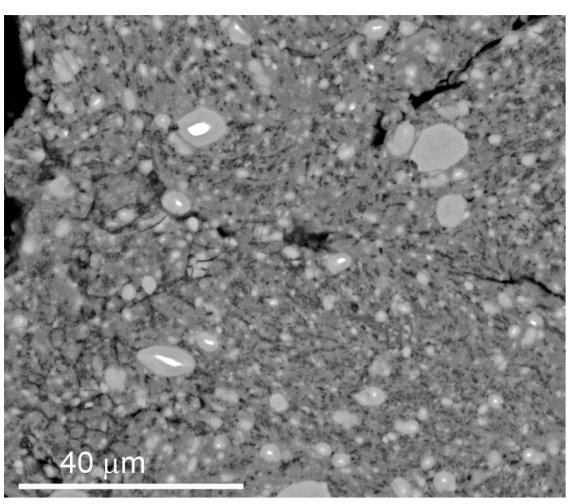

(a)

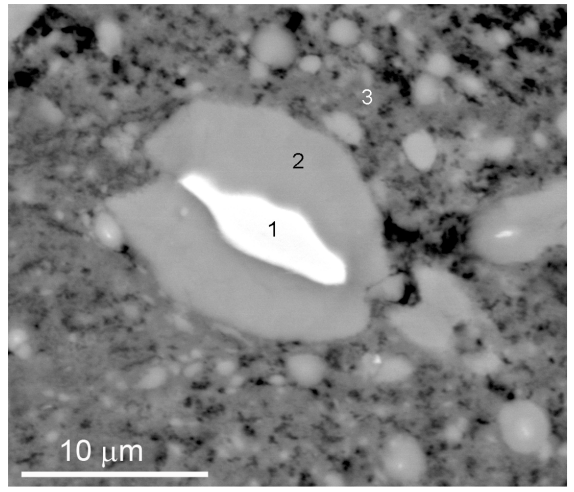

\begin{tabular}{|c|c|c|c|}
\hline Spot & $\mathrm{Fe}(\mathrm{wt} \% / \mathrm{at} \%)$ & $\mathrm{Cr}(\mathrm{wt} \% / \mathrm{at} \%)$ & $\mathrm{Al}(\mathrm{wt} \% / \mathrm{at} \%)$ \\
\hline 1 & $74.5 / 68.8$ & $19 / 18.8$ & $6.5 / 12.4$ \\
\hline 2 & $28.8 / 17.1$ & $7.6 / 4.9$ & $63.6 / 78.0$ \\
\hline 3 & $17.0 / 9.2$ & $4.7 / 2.8$ & $78.3 / 88.0$ \\
\hline
\end{tabular}

(b)
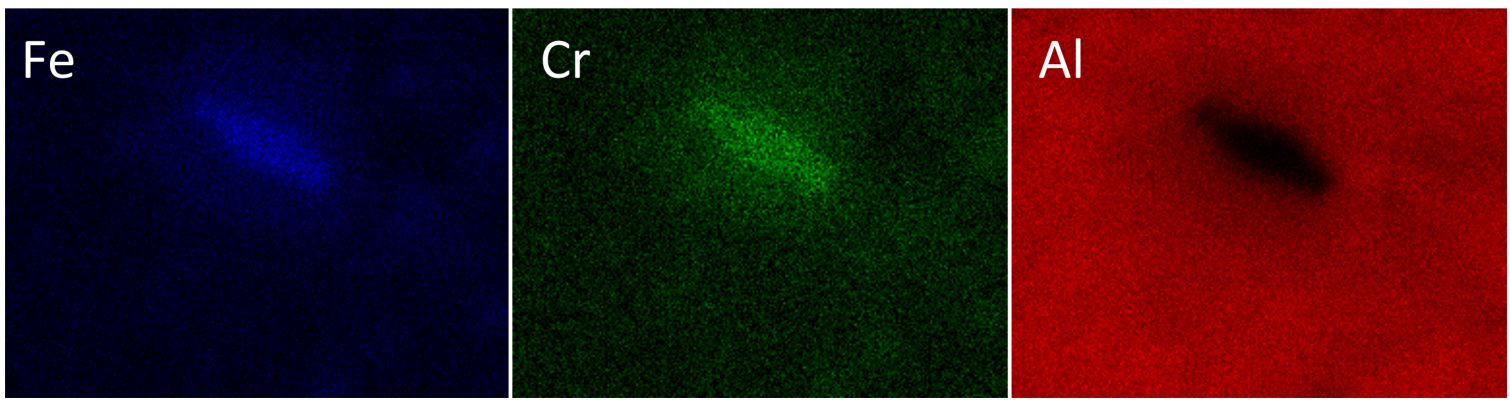

(c)

Figure 6. (a) and (b) Backscattered image of a Al_10 vol.\% MA956 composite powder heated up to $570{ }^{\circ} \mathrm{C}$. Inserted table in (b) presents the EDS results obtained from spots 1, 2 and 3. (c) EDS mapping showing the distribution of $\mathrm{Fe}, \mathrm{Cr}$ and $\mathrm{Al}$ in the region of Figure $6 \mathrm{~b}$. 
as the temperature is higher or as the diffusion distances are smaller (periphery of the reinforcing particles). Chromium seems to diffuse in the opposite direction, since there was depletion of this element in the $\alpha$-Fe phase.

The results showed that the MA956 alloy is not stable under heat treatments at $420{ }^{\circ} \mathrm{C}$ and $570{ }^{\circ} \mathrm{C}$. The results related to phase stability are very important to define the parameters for subsequent hot consolidation processing, as for instance the definition of the extrusion temperature. Extrusion of aluminum alloys are usually performed at temperatures between $400{ }^{\circ} \mathrm{C}$ to $450{ }^{\circ} \mathrm{C}$. The results showed that at $420{ }^{\circ} \mathrm{C}$ for $1 \mathrm{~h}$ the reaction between reinforcement particles and aluminum matrix was partial. So, it can be expected that during the extrusion process that takes a few minutes at typical speeds of $2 \mathrm{~mm} / \mathrm{s}$, the reaction will occur in an even less extensive way.

The stability of the reinforcement phase is also more important if the matrix is an age hardenable aluminum alloy, once a solution heat treatment step would be necessary which normally takes place at temperatures of about $500^{\circ} \mathrm{C}$.

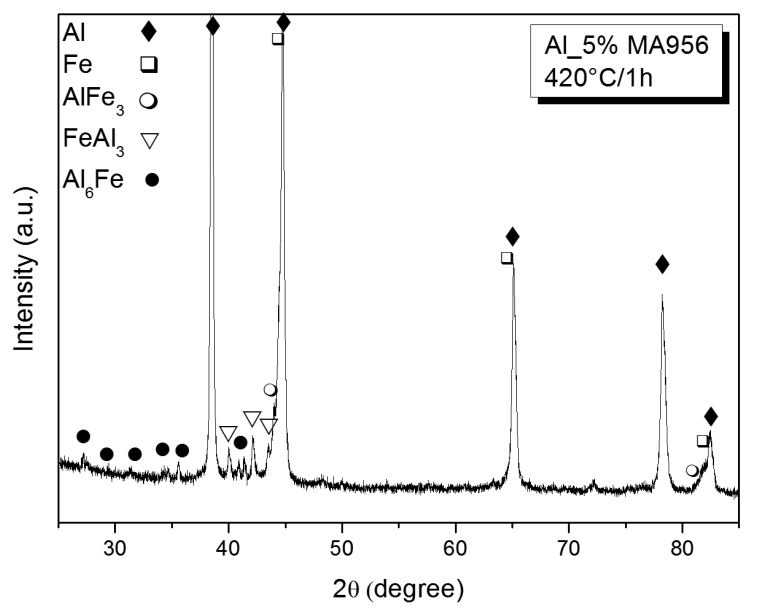

(a)

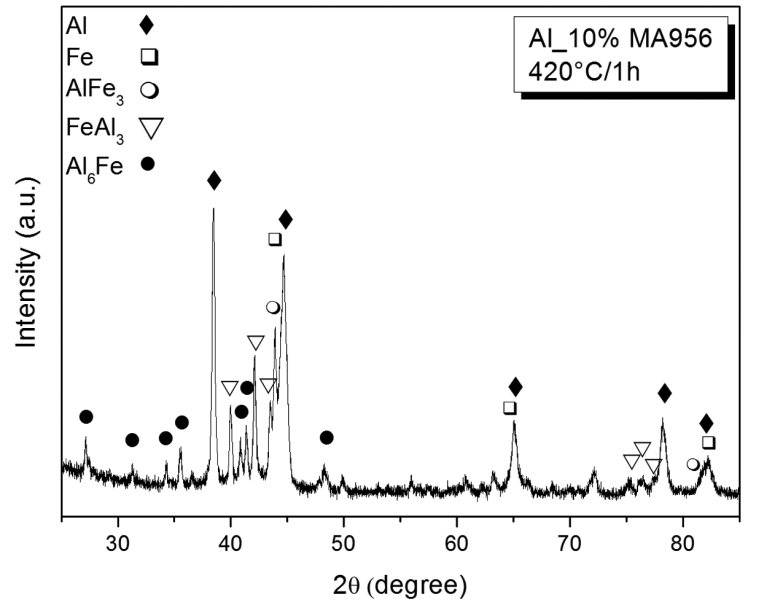

(c)
Lieblich et al. ${ }^{10,15}$ have studied the stability of aluminum and aluminum alloys reinforced by the intermetallic phase $\mathrm{Ni}_{3} \mathrm{Al}$ and showed that when the unalloyed $\mathrm{Al}$ was used the composite was thermally stable at $300^{\circ} \mathrm{C}$ up to $1000 \mathrm{~h}$. Above this temperature, dissolution of $\mathrm{Ni}_{3} \mathrm{Al}$ occurred with formation of an outer $\mathrm{Al}_{3} \mathrm{Ni}$ layer and an intermediate $\mathrm{Al}_{3} \mathrm{Ni}_{2}$. However, when the composite matrix was an alloy as the AA6061, the reaction product contained alloying elements as $\mathrm{Si}$ and $\mathrm{Mg}$, and as a consequence, the age hardenability of the alloy was lost because of the depletion of solute elements in the matrix during the solution treatment. The mechanical properties of AA2124 aluminum alloy reinforced with several intermetallic particles as $\mathrm{Ni}_{3} \mathrm{Al}, \mathrm{NiAl}, \mathrm{Cr}_{3} \mathrm{Si}$ and $\mathrm{MoSi}_{2}$ were founded directly related with the thermal stability of the composites during processing and subsequent thermal treatment. The best properties were presented by the most thermally stable system ${ }^{8}$.

Recently, Xue et al. ${ }^{16}$ have showed that a core-shell structured particulate reinforced Al matrix composite as presented in this work in Figure 5a, can be beneficial for

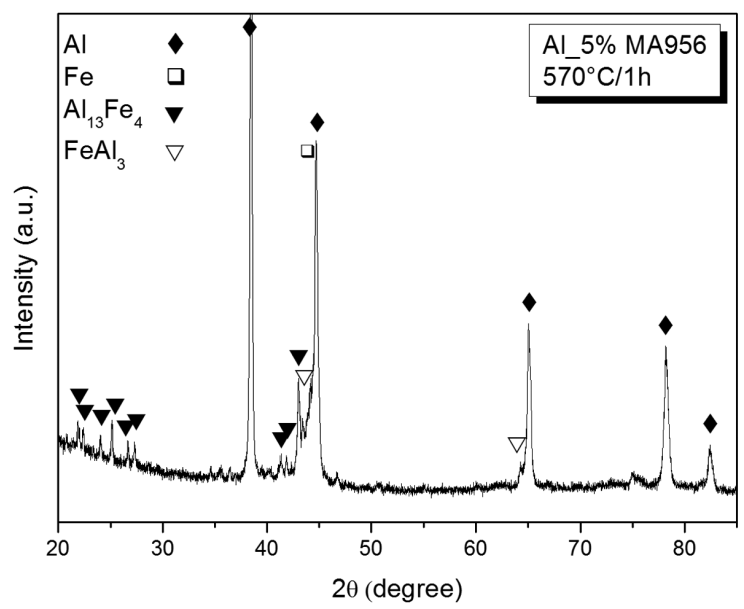

(b)

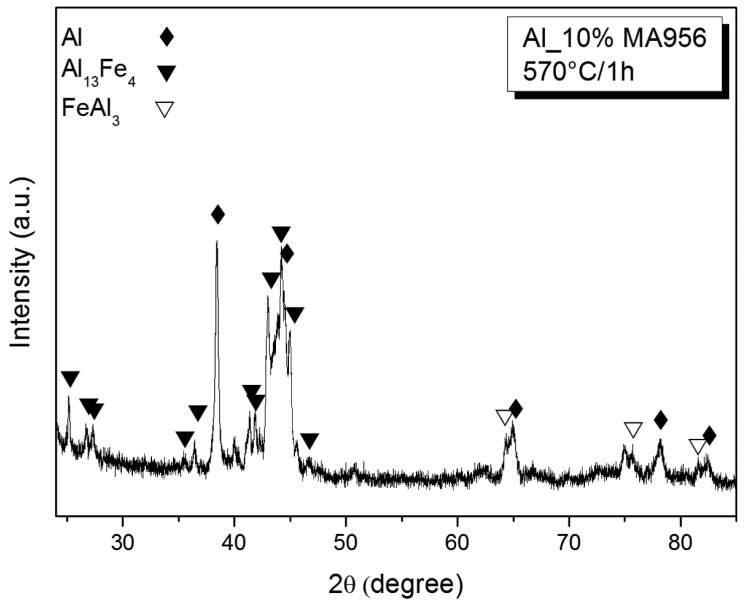

(d)

Figure 7. XRD patterns of composite samples after milling for $50 \mathrm{~h}$. (a) Al 5 vol.\% MA9556 after heat treatment at $420{ }^{\circ} \mathrm{C} / 1 \mathrm{~h}$; (b) Al 5 vol.\% MA9556 after heat treatment at $570{ }^{\circ} \mathrm{C} / 1 \mathrm{~h}$; (c) Al_10 vol.\% MA9556 after heat treatment at $420{ }^{\circ} \mathrm{C} / 1 \mathrm{~h}$ and (d) Al_10 vol.\% MA9556 after heat treatment at $570{ }^{\circ} \mathrm{C} / 1 \mathrm{~h}$. 
mechanical properties as the soft Al matrix and soft Fe core could effectively inhibit the crack propagation once cracks are nucleated from the intermetallic shell during plastic deformation, resulting in the preservation of the ductility as well as the improved strength.

Extrusion of the composites obtained by mechanical alloying in the present paper in the temperature range of about $400-450{ }^{\circ} \mathrm{C}$ followed by a microstructural and mechanical characterization of extruded samples are goals for the next stage of development of this research.

\section{Conclusions}

Composites Al_MA956 with 5 and 10 vol.\% were successfully produced by mechanical alloying (MA). A fine and homogeneous dispersion of the MA956 reinforcement particles was obtained after $20 \mathrm{~h}$ of milling. The evolution of morphology and particle size of composite powders was the

\section{References}

1. Pour HA, Lieblich M, Shabestari SG and Salehi MT. Influence of pre-oxidation of NiAl intermetallic particles on thermal stability of Al/NiAlp composites at $500{ }^{\circ} \mathrm{C}$. Scripta Materialia. 2005; 53(8):977-982. http://dx.doi.org/10.1016/j.scriptamat.2005.06.023.

2. Miracle DB. Metal matrix composites: from science to technological significance. Composites Science and Technology. 2005; 65(15-16):2526-2540. http://dx.doi.org/10.1016/j. compscitech.2005.05.027.

3. Lindroos VK and Talvitie MJ. Recent advances in metal matrix composites. Journal of Materials Processing Technology. 1995; 53(1-2):273-284. http://dx.doi.org/10.1016/0924-0136(95)01985-N.

4. Rosso M. Ceramic and metal matrix composites: routes and properties. Journal of Materials Processing Technology. 2006; 175(13):364-375. http://dx.doi.org/10.1016/j.jmatprotec.2005.04.038.

5. Kaczmar JW, Pietrzak K and Wlosinski W. The production and application of metal matrix composite materials. Journal of Materials Processing Technology. 2000; 106(1-3):58-67. http://dx.doi.org/10.1016/S0924-0136(00)00639-7.

6. Torres B, Wang Y, Lieblich M, Ibañez J, Rainforth WM and Jones $\mathrm{H}$. Interfacial reactions between the aluminium alloy matrix and intermetallicreinforcement particles in novel $\mathrm{P} / \mathrm{M}$ 5056/Ni3AlP composites. Zeitschrift fur Metallkunde. 2001; 92(6):604-609

7. Wang Y, Rainforth WM, Jones H and Lieblich M. Dry wear behavior and its relation to microstructure of novel 6092 aluminum alloy-Ni3 Al powder metallurgy composite. Wear. 2001; 251(1-12):1421-1432. http://dx.doi.org/10.1016/S00431648(01)00783-9.

8. Torres B, Lieblich M, Ibañez J and García-Escorial A. Mechanical properties of some PM aluminide and silicide reinforced 2124 aluminium matrix composites. Scripta Materialia. 2002; 47(1):45-49. http://dx.doi.org/10.1016/S1359-6462(02)00095-7. typical observed in MA. At the first stage, the simultaneous plastic deformation and cold welding resulted in the formation of a layered structure. As the milling progresses the reinforcement trapping between the aluminum particles and the work hardening enhanced the fracture process reducing the particle size. The composite powders produced with 10 vol.\% MA956 presented a more accentuated decrease in particle size during the milling, reaching $37 \mu \mathrm{m}$ after $50 \mathrm{~h}$. The heat treatment at $420{ }^{\circ} \mathrm{C}$ resulted in partial reaction between matrix and reinforcement particles, while at $570{ }^{\circ} \mathrm{C}$ the extension of reaction was overall, with formation in both cases of intermetallic phases rich in aluminum.

\section{Acknowledgements}

The authors acknowledge CAPES for the grant of LAC Moutinho Gomes (“Jovens Talentos" Program) and ALCOA for the aluminum powder.

9. Torres B and Lieblich M. Room and high temperature tensile behavior of a P/M 2124/MoSi ${ }_{2}$ composite at different heat treatment conditions. Journal of Materials Science. 2006; 41(11):3493-3500. http://dx.doi.org/10.1007/s10853-005-5678-1.

10. Lieblich M, Gonzalez-Carrasco JL and Caruana G. Thermal stability of an $\mathrm{AlNi}_{3} \mathrm{Al}$ composite processed by powder metallurgy. Intermetallics. 1997; 5(7):515-524. http://dx.doi.org/10.1016/ S0966-9795(97)00027-7.

11. Chao J, Cristina MC, González-Carrasco JL and GonzálezDoncel G. Efecto del procesado termomecánico sobre las propiedades mecánicas de la aleación MA956. I. Caracterización microestructural. Revista de Metalurgia. 1998; 34:211-215. http://dx.doi.org/10.3989/revmetalm.1998.v34.iExtra.740.

12. Hupalo MF, Terada M, Kliauga AM and Padilha AF. Microstructural characterization of INCOLOY alloy MA 956. Materialwissenschaft und Werkstofftechnik. 2003; 34(5):505508. http://dx.doi.org/10.1002/mawe.200390100.

13. Fleck NA, Muller GM, Ashby MF and Hutchinson JW. Strain gradient plasticity: theory and experiment. Acta Metallurgica et Materialia. 1994; 42(2):475-487. http://dx.doi.org/10.1016/09567151(94)90502-9.

14. Kamrani S, Simchi A, Riedel R and Seyed Reihani SM. Effect of reinforcement volume fraction on mechanical alloying of al_sic nanocomposite powders. Powder Metall. 2007; 50(3):276-282. http://dx.doi.org/10.1179/174329007X189621.

15. Torres B, Lieblich M and García-Escorial A. Effect of heat treatments at $520^{\circ} \mathrm{C}$ on an aluminium alloy matrix composite reinforced with $\mathrm{Ni}_{3} \mathrm{Al}$ powder particles. Scripta Materialia. 2006; 54(8):1485-1489. http://dx.doi.org/10.1016/j.scriptamat.2005.12.052.

16. Xue Y, Shen R, Ni S, Song M and Xiao D. Fabrication, microstructure and mechanical properties of Al-Fe intermetallic particle reinforced Al-based composites. Journal of Alloys and Compounds. 2015; 618:537-544. http://dx.doi.org/10.1016/j. jallcom.2014.09.009. 